\title{
Robot-Mediated Interventions to Enhance Communication and Social Abilities of Children and Youth with Disabilities: a Review of the Literature
}

\author{
Jiyeon Park ${ }^{1}$, Ye Eun Baek², Bo Lyeong $\mathrm{Lim}^{2}$ and Heeseon Ko \\ 'Department of Special Education, Ewha Womans University, Seoul, Korea \\ ${ }^{2}$ Special Education Research Institute, Ewha Womans University, Seoul, Korea \\ ${ }^{3}$ Graduate Program in Special Education, Ewha Womans University, Seoul, Korea
}

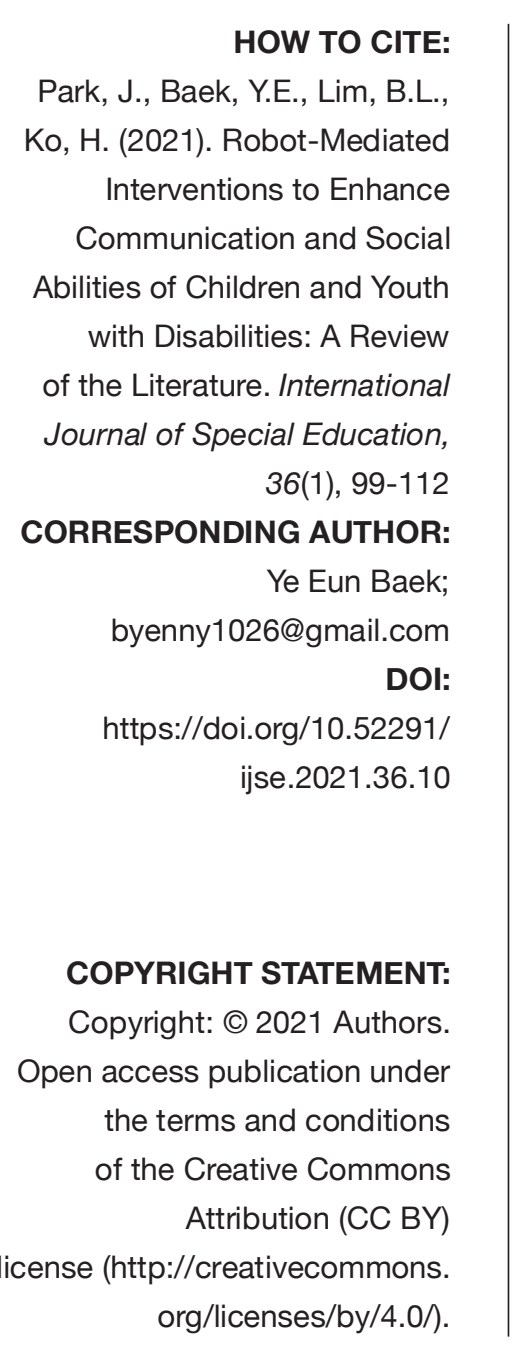

HOW TO CITE:

Park, J., Baek, Y.E., Lim, B.L., Ko, H. (2021). Robot-Mediated Interventions to Enhance Communication and Socia Ailities of Children and Youth with Disabilities: A Review of the Literature. Internationa 36(1), 99-112

Ye Eun Baek

DOI:

ijse.2021.36.10

\begin{abstract}
Objectives: The current paper presents a review of the literature discussing the trends in research that conducted robot-mediated interventions to enhance communication and social abilities of children and youth with disabilities. Method: Thirty-two dissertation or research articles published after 2000 were selected and divided into thematic categories for analysis, including participants, setting, research method, characteristics of robot-mediated interventions, roles of robots, and the results of studies. Results: First, the research most frequently focused on children and youth with Autism Spectrum Disorders. Second, most of the research was conducted in educational settings. Third, most research used quantitative research design, in particular a single-subject research design method was the most common. Fourth, in most of the research humanoid robots assisted the intervention, acting as an interaction partner of participants and as an instrumental medium to prompt the participants to demonstrate desirable behavior. Finally, most studies reported positive effects of robot-mediated intervention in the communication and social abilities of children and youth with disabilities. Conclusion: The paper provides the outcomes and limitations of robot-mediated interventions for children and youth with disabilities and the implications for future research.
\end{abstract}

Keywords: robot-mediated intervention, children and youth with disabilities, literature review, humanoid, communication, social ability 


\section{INTRODUCTION}

In the field of special education, the use of robots began in 1970 for the purpose of engineering to provide walking assistance for people with visual impairments and those with physical disabilities including the elderly. Among the first robots used were the walking aid robot "Sil-Bo" developed in Korea, the robot suit „HAL” in Japan, „Care-O-bit” in Germany, and "Nursebot” in the US (Kim \& Song, 2012). In addition to engineering applications, robots can also be used for the purpose of assisting the education and therapy of children and youth with disabilities or motivating and promoting their participation (Kim, Lee, Shin, Kang, Kim, Choi, \& Song, 2012).

Robots generally enable simple, consistent, and predictable interactions with users through systematic programming, and they also promote interactions with the users such as providing children and youth with immediate feedback (Choi, 2015). The physical appearance of robots induces children's and youth's interests and curiosity, and their audiovisual stimuli can themselves serve as rewards. Furthermore, the mobility and fluidity of the robots enable active interaction with the users, such as touching and manipulating body positions and thus, providing a sense of vitality (Choi, 2015). These characteristics of the robots were found to have positive effects on promoting social interaction and improving communication skills of children and youth with disabilities (Kim, Lee, Chang, \& Bae, 2011; Kim \& Shin, 2014). Moreover, robots have positively impacted children's and youth's psychological aspects, for example, children and youth who have interacted with robots recognize them as friendly objects or experience decreased anxiety (Kim \& Han, 2005).

Many domestic and international research teams have developed robots for educational and therapeutic purposes of children and youth with disabilities (Choi, 2015). The "KASPAR" of the AuRoRa Project, the "Bandit" robot, and the "Keepon," were developed abroad; and a humanoid robot named "Engkey," initially developed for English education, and intelligent robots such as "Irobi" and "Pleo" were developed in Korea for language and communication skills, eye contact and facial expression reading skills, and social behavior of children and youth with ASD (Kim, Lee, Shin, Kang, Kim, Choi, \& Song, 2012; Kim \& Song, 2012; Yun et al., 2015).

Children and youth with ASD, who have appeared most often as participants in robot-related research, exhi- bit limited, repetitive, and stereotyped behaviors, interests, and activities (Kim, Lee, Chang, \& Bae, 2011). Moreover, children and youth with ASD do not appear to use or hardly use non-verbal communication behavior, such as eye contact or facial expressions, and due to lack of social communication skills-such as lack of emotional sharing with others, imitation, and joint attention skills-they can experience difficulty in social interactions (Lee \& Park, 2011). Examining the research that conducted robot-mediated interventions for children and youth with disabilities, it has been reported that children and youth with ASD were not afraid of robots; rather, they seemed to feel psychologically stable from the simple and predictable behavior of the robot, as seen in the observation of children interacting well and imitating the behavior of the robot even when they were in unfamiliar contexts (Dautenhahn \& Billard, 2002).

Furthermore, several studies have reported that robots appeared to play a role of social mediator in facilitating communication and social interactions among children and youth with ASD (Fachantidis et al., 2020; Kim, Lee, Chang, \& Bae, 2011). For instance, Fachantidis and his colleagues (2020) conducted a robot-mediated cooperative activity program for a small group of children and youth with ASD and their peers without disabilities. It was found that children and youth with ASD showed improvement in their social skills and communication skills and a decrease in challenging behaviors, and also the peers without disabilities who participated in the intervention perceived children and youth with ASD more positively than before. These research studies show that robot-mediated intervention positively affects initiative, autonomy, preference exploration, and the formation of new methods of interaction among children and youth with ASD. It also reduces teachers' efforts to conduct behavioral modeling or to analyze the task when guiding children and youth with ASD. Accordingly, the research indicated that these interventions increased the concentration and participation rate of children and youth with disabilities and their peers who participated in the intervention by stimulating their interests and curiosity (Charron, Lewis, \& Craig, 2017; Kim, Lee, Chang, \& Bae, 2011).

As discussed above, the results of studies show that children and youth with ASD are more engaged in interactions with automatic and fluid robots than rigid, repetitive, and non-interactive toys and to date, numerous studies on robots for children and youth with ASD have been reported (Choi, 2015). However, considering the 
importance of inclusive education settings, in which children and youth with disabilities and their peers without disabilities are integrated, robot-mediated interventions need to be applied to children and youth with diverse disabilities. According to some previous studies, robots have appeared to facilitate acquisition of communication skills including articulation, voluntary conversation, and verbal participation of children with disabilities (Silvera -Tawil, Bradford, \& Roberts-Yates, 2018). In addition, there is an increasing interest in the field of socially-assistive robotics, which improves communication skills and social abilities of children with disabilities through practical social interactions with robots (Silvera-Tawil \& Roberts-Yates, 2018).

Children and youth having emotional and behavioral problems, for example, can experience difficulties in social interactions with people around them and engage in behavior that is undesirable and inappropriate for the situation and their age due to various causes such as lack of social skills and performance (Kim \& Shin, 2014). With regard to this, researchers have aimed to improve social skills of children and youth with disabilities and provide them with diverse learning opportunities by utilizing various functions of robots such as expressing emotions very similar to those of humans, having diverse and active interactions through mobility and fluidity, and providing immediate feedback according to the student's reaction to the robots (Kim \& Shin, 2014; Shin \& Kim, 2014). Moreover, a recent study examined the effectiveness of animal-type social robots (iJINI) on improving verbal and social interactions of children and youth with physical disabilities and the satisfaction of their parents with regard to the robot (Song, Kim, \& Kwak, 2020).

Thus, research using robots, which until recently was only in its early stages, seems to be gradually diversifying the area of robot use, reflecting over time the different individual needs and requirements of users. In the past research, robots have been mainly used in social technology-oriented programs, but they are used increasingly more often in the areas of language, cognitive and academic skills, and behavior (Kim \& Shin, 2014). As discussed above, research studies that conducted robotmediated interventions for children and youth with disabilities are expanding further in terms of the diversity of targeted children and youth and functions of robots. The introduction and the uses of robot technology in the educational field is a strategy that can provide useful support in the education and therapy of children and youth with diverse and complex needs, such as the areas of concentration, motivation, social abilities and repetitive learning (Choi, 2015).

In this study, we searched for and selected research that employed robots as a medium for interventions targeting communication and social abilities of children and youth with disabilities for the past 20 years, and we conducted a systematic analysis by categories. Through this, we examined the outcomes and limitations of robot-mediated interventions for children and youth with disabilities and presented the implications for future research. Moreover, this study endeavors to provide robot developers with a basis for developing functions that can be practically applied to interventions for children and youth with disabilities and to provide educational experts, who develop content for robot-mediated interventions, with a knowledge base to be considered when they develop contents and strategies for those interventions.

The research questions for this study are as follows: first, what has been the overall trend of research using robots to improve communication and social abilities of children and youth with disabilities in Korea and other countries since 2000 ? Second, what is the trend in research by category, especially with regard to the types and roles of robots and the main subjects of the independent variables?

\section{METHOD}

\section{Search strategy and the research selection process}

The review is based on dissertations or research articles that conducted robotic interventions for children and youth with disabilities and were originally published between January 2000 and September 2020. The electronic databases searched were ERIC, RISS, and Google Scholar, and the keywords used to identify the articles were (a) "disability*," "autism," "ASD," "intellectual disability*," or "ADHD"; and (b) "robot," "artificial intelligence," and "AI." The search on Google Scholar was implemented as an initial step, and then the formal search was done in the rest of the databases, including ERIC and RISS. Looking at whether articles retrieved on Google Scholar could be selected for analysis based on the title and abstract of each article, it was found that a large number of articles were not directly related to the entered keywords and the selection criteria of this study. Accordingly, a formal search of the remaining databa- 


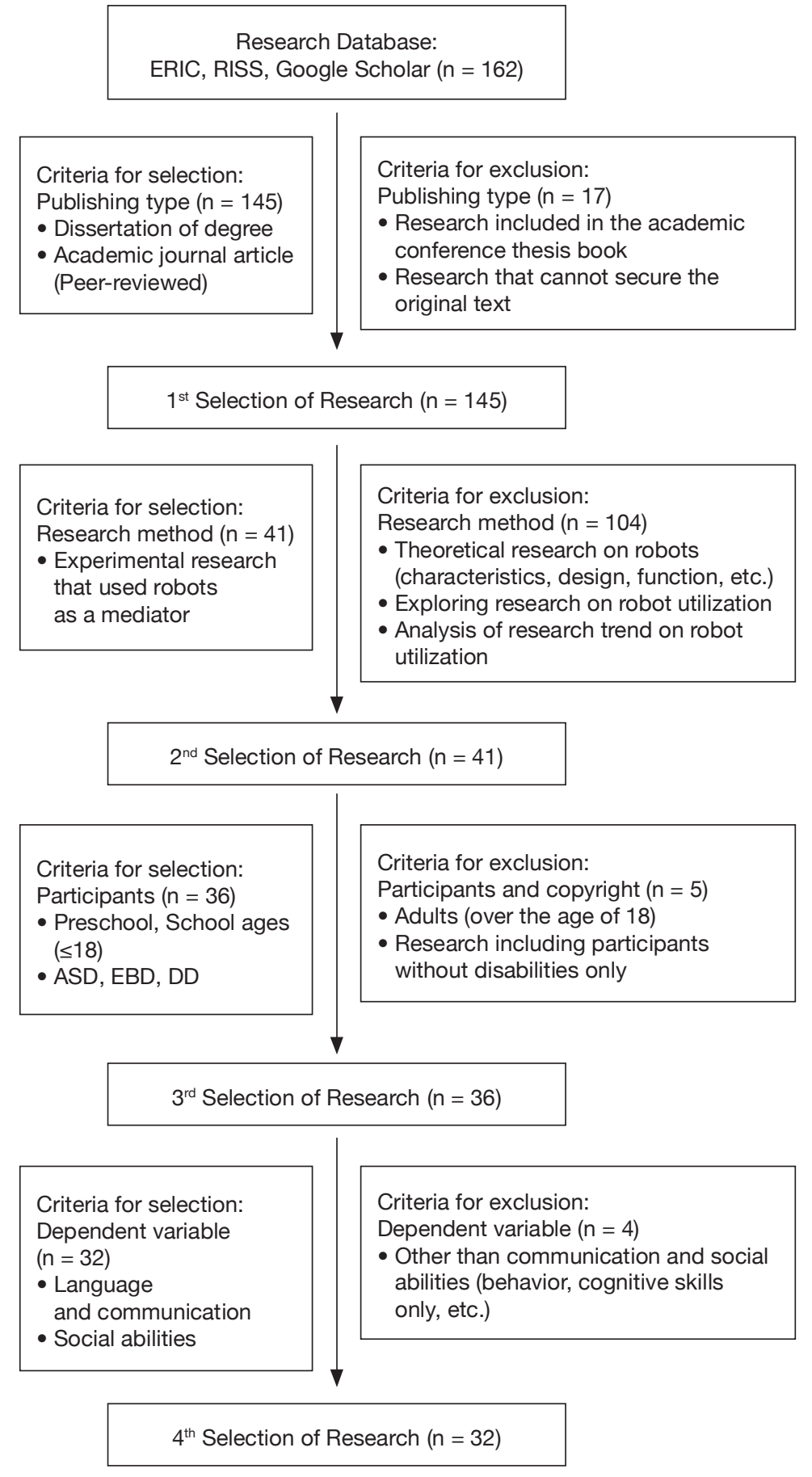

Figure 1.

Procedure for selecting research to be analyzed

ses was conducted. A total of 1,384 articles were exported from the electronic database search. After reviewing the article titles and abstracts, any research articles that were not related to disability and robots were excluded, and if the dissertation was published in an academic journal, it was considered appropriate for the study. This search process yielded 162 articles. Overall, it was found that many studies were focused on communication or social abilities of children and youth with disabilities.
The following inclusion criteria were employed: (a) dissertation or academic journal articles that were published after January 2000; (b) articles on experimental studies that directly utilize robots for interventions, such as a robot leading or assisting the intervention; (c) articles on studies that include children and youth with disabilities as participants; (d) articles examining communication and/or social abilities as a dependent variable. The following exclusion criteria were employed: (a) articles published only at academic conferences and articles where the original text cannot be secured due to the lack of copyright consent; (b) theoretical studies related to robots, research on the possibility of using robots, and research on trends in using robots; and (c) articles on research using robots only for adults and children and youth without disabilities. This process resulted in 32 research articles in total for the systematic review (See Figure 1).

\section{Analysis methodology}

The selected 32 studies were analyzed by classifying them into categories such as participants, environment, types and roles of robots, types of independent variables, dependent variables, and overall research findings. In order to understand the trends of participants, age, school level, disability types, and number of participants in each study were examined. To examine the trends in the intervention settings, the study was coded as "schools", "controlled settings such as therapy rooms", "mixed settings including more than one place", "home", and "settings not specified". In addition, the research method was analyzed by categories including a quantitative research, a qualitative research, and a mixed research design. In order to understand the current status of robot technology being used for communication and social intervention of children and youth with disabilities, the types of robots used in the intervention were coded as "a humanoid robot" and "a non-humanoid robot", and the roles of the robots in the intervention were coded as "an intervention assistant" and "an intervention leader". Types of interventions using robots were examined according to language, 
9

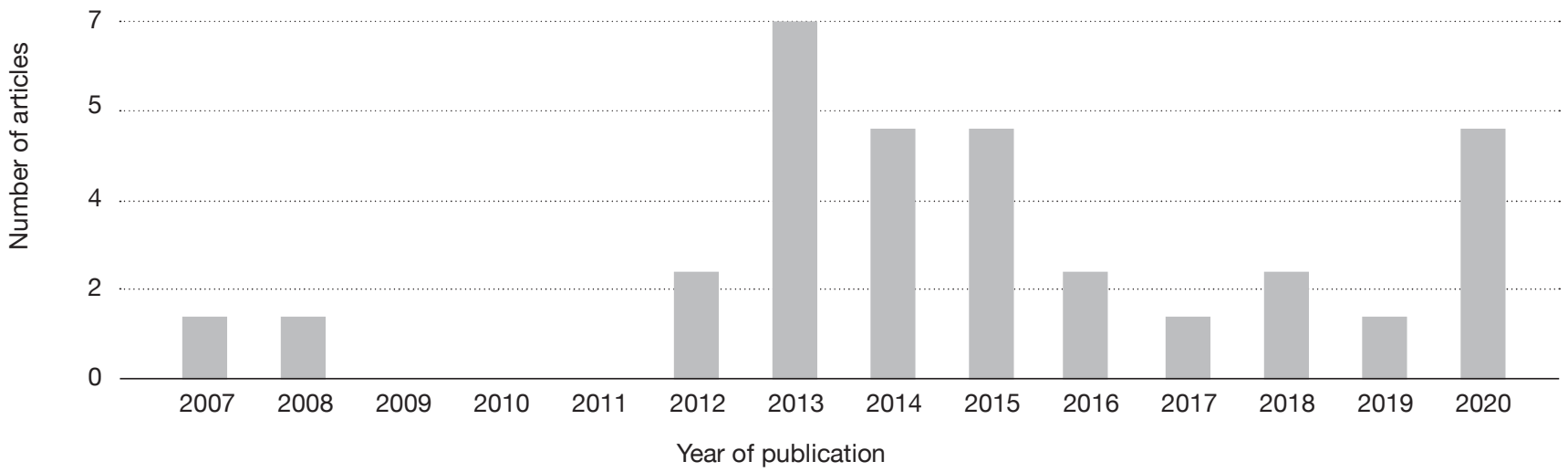

Figure 2.

Number of articles by the year of publication

academic skills, and social emotional competence. The dependent variables were coded as communication and social abilities; and social abilities were in turn subdivided into social interaction, joint attention, social interaction behavior in play, and others.

\section{Inter-rater reliability}

While there are literature review studies in which raters independently analyze studies based on variables and calculate its consistency, this study conducted an analysis based on the previous study (Fettig \& Barton, 2013) that measured the inter-rater reliability in a unanimous manner through consultation. The authors developed definitions for each analysis variable and used a spreadsheet to record information from the 32 studies. The following variables were coded across 32 studies: "the participants", "the settings", "the types(name) of the robot" and "its roles in the intervention", "independent variables", "dependent variables", and "overall outcomes". At least two authors independently coded each study and compared the spreadsheet with each other. Disagreements were discussed until authors reached a consensus. However, such disagreement only occurred twice in determining whether the robot in two studies played an actual role in the intervention. The overall agreement between the two authors was calculated by dividing the number of agreements by the number of agreements plus disagreements. The overall agreement was $99 \%$.

\section{RESULTS}

Looking at the overall trend of 32 selected articles by the year of publication, the largest number of articles on robot-mediated interventions was published in 2013, followed by five articles, each in 2014, 2015, and 2020. None of the articles published between 2009 and 2011 met the selection criteria for this study, and over the rest of the period, at least one article was published that met the selection criteria for this study (See Figure 2). The results of the analysis of 32 articles are summarized in Appendix 1 .

\section{Analysis of study by category}

\section{1-1. Participants}

According to the review of 32 articles, 15 studies were conducted on preschoolers, accounting for $46.9 \%$ of the total, whereas 11 studies on elementary school students accounted for $34.4 \%$. There were five studies (15.6\%) conducted on a mixture of preschoolers and elementary school students, and one study (3.1\%) was conducted on middle school students.

In terms of the type of disability among the study participants, ASD was the most common among 26 studies $(81.3 \%)$, followed by EBD in three studies $(9.3 \%)$. In the others, there were two studies $(6.3 \%)$ on developmental delay (DD) and one (3.1\%) on "minimally verbal" children.

\section{1-2. Setting}

The research settings were analyzed by five categories including 1) educational settings such as general education classrooms, special education classrooms, and daycare centers, 2) controlled settings such as therapy rooms and laboratories, 3) mixed settings including more than one place such as natural settings and controlled settings, 4) 
home, and 5) settings not specified. Among 32 studies, 15 studies $(46.9 \%)$ took place in the educational settings and 11 studies (34.4\%) in therapy rooms and laboratories. Two studies $(6.3 \%)$ were conducted in more than one place including daycare centers and laboratories, and only one study $(3.1 \%)$ was conducted in the participants' home. Other than that, three studies $(9.3 \%)$ did not specify the research settings.

\section{1-3. Research method}

According to the result of analysis, the most common research design was quantitative research, which was used in 27 studies (accounting for $84.4 \%$ of the total), followed by four studies $(12.5 \%)$ using a qualitative research design. In addition, there was also one study (3.1\%) using a mixed research design that conducted both quantitative and qualitative research. In 27 quantitative research studies, 21 studies examined the intervention effect on a single subject and six studies proving the intervention effect through comparison between the groups. Furthermore, among the experimental design methods used to prove the effect of robot-mediated intervention in single -subject research studies, the reversal design and the multi -baseline design across subjects proved the most popular, followed by the pretest-posttest control group design.

\section{Analysis of independent variables}

\section{2-1. Types of robots used for intervention}

The robots used in the intervention could be classified into (1) humanoid robots that have human-like facial and physical features and that can perform functions like humans, such as interactions, and (2) non-humanoid robots, including robots with animal or character shapes. Seven types of humanoid robots were used in 28 studies (87.5\%), of which two types of humanoid robots were used in the studies of Yun et al. (2015) and Lee et al. (2016). Six types of non-humanoid robots were used in six studies $(18.8 \%)$, of which both a humanoid robot and a non-humanoid robot were used in the study of Lee et al. (2016).

\section{2-2. Types of robot-mediated interventions}

The types of interventions using robots were categorized into language, academic skills, and social emotional competence, including joint attention, expression, imitation. There were seven studies using robots to develop language and academic skills of children and youth with disabilities, and 27 studies were focused on the social emotional competence area (duplicate analyzed studies included).
Among the 27 studies using robots in the social emotional competence area, nine studies focused on improving joint attention skills. It can be inferred from this that there has been an attempt to apply the method of using robots in interventions to improve the skills that children and youth with ASD, who have most often appeared in robot -related studies, have the most difficulty with.

\section{2-3. Roles of robots in intervention}

The roles of the robots used in the intervention was categorized into leading intervention and assisting intervention. In 15 studies ( $46.9 \%$ of the total), the role of "leading intervention" was given for minimizing the involvement of teachers in general and allowing the robot to lead the content for each session. Robots played a role of presenting learning content and stimuli in the process of conducting activities with children and youth or while providing responses and feedback according to the actions of children and youth. In particular, the robot-driven instruction is programmed in advance to output the input content or allow the researcher to remotely control the class while viewing the class situation through the camera built into the robot to immediately respond to children's and youth's behavior and provide a feedback (Bekele et al., 2014; Charron et al., 2017; Huskens et al., 2015; Pop et al., 2013; Yun et al., 2015; Zheng et al., 2020).

However, when the robot was used as an assistant, it was most often used as a social mediator or peer to the participants to promote the target behaviors of children and youth (eight of 17 studies). Subsequently, in another eight studies, the teacher controlled the content loaded into the robot in advance, allowing the robot to output it at the appropriate time during class, or used the robot as one of the classroom tools, such as for augmentative and alternative communication (AAC) or as a student modeling target. In addition, the robot presented quiz questions related to classroom activities and played a role in checking whether the children's answers were provided correctly (Jeong, 2015).

\section{Analysis of dependent variables}

The dependent variables of 32 articles were categorized into communication and social abilities. The results of the analysis of dependent variables are shown in Table 1. Ten studies examined the effectiveness of robot-mediated intervention in improving communication skillssuch as self-directed questioning, sight word acquisition, 
Table 1.

Analysis of dependent variables

\begin{tabular}{|c|c|c|c|}
\hline Dependent Variable & Category & Research & $\mathbf{n}$ \\
\hline Communication & $\begin{array}{l}\text { Language } \\
\text { and Communication }\end{array}$ & $\begin{array}{l}\text { Shin (2012) *, Bae et al. (2013a) *, Huskens et al. (2013), Kwon et al. (2013), } \\
\text { Jeon (2014), Lee (2014), Han (2015), Jeong (2015), Saadatzi et al. (2018), } \\
\text { Fachantidis et al. (2020) * }\end{array}$ & 10 \\
\hline \multirow[t]{4}{*}{ Social Abilities } & Social interaction & $\begin{array}{l}\text { Robins et al. (2007), Duquette et al. (2008), Pop et al. (2014), Bekele et al. } \\
\text { (2014), Yun (2015), Simut et al. (2016) *, Charron et al. (2017), Kim (2018), } \\
\text { So et al. (2019) *, Conti et al. (2020), David et al. (2020), Zheng et al. (2020) }\end{array}$ & 12 \\
\hline & $\begin{array}{l}\text { Joint attention } \\
\text { (initiating } \\
\text { and responding behavior) }\end{array}$ & $\begin{array}{l}\text { Kim (2012), Shin }(2012){ }^{*} \text {, Bae (2013) }{ }^{*}, \text { Kim et al. }(2013){ }^{*}, \text { Kim et al. (2014), } \\
\text { Shin et al. (2014), Lee et al. (2016) }{ }^{*}\end{array}$ & 7 \\
\hline & $\begin{array}{l}\text { Social interaction } \\
\text { behavior in play }\end{array}$ & $\begin{array}{l}\text { Bae }(2013) \text { *, Bae et al. }(2013 a) * \text {, Bae }(2013 b), \text { Kim et al. }(2013) \text { *, Lee et al. } \\
(2016){ }^{*} \text {, So et al. }(2019)^{*}\end{array}$ & 5 \\
\hline & Others & $\begin{array}{l}\text { Shin (2012), Huskens et al. (2015), Park et al. (2015), Simut et al. (2016) *, } \\
\text { Fachantidis et al. (2020) *, Kostrubiec et al. (2020) }\end{array}$ & 7 \\
\hline
\end{tabular}

${ }^{*}$ Research article with duplicate analysis

and the ability to express phrases_-of children and youth with disabilities through interactions with robots.

Among the selected studies, 25 studies had social abilities as a dependent variable, and these studies were categorized based on which part of the social abilities was targeted. Accordingly, social abilities were again classified into four categories, including social interaction, joint attention (initiating and responding behavior), social interaction behavior in play, and others. Most of the studies, including Duquette and her colleagues (2008), conducted robot-mediated interventions to improve the social abilities of children and youth with disabilities. Among them, most (12 studies) confirmed their effectiveness in social interactions, such as imitation, eye contact, and turn-taking skills, followed by seven studies that focused on improving initiating and responding behavior (joint attention). Five studies examined participants' social interaction behavior in play, such as the selection of play materials and diversity of play methods through interacting activities with robots. Moreover, seven studies confirmed the effectiveness of robot-mediated interventions in other subcategories of social ability, such as caregiving behavior, cooperative behavior, and task performance.

\section{Analysis of study results}

Most of the studies reported positive effects of robot-mediated intervention in communication and social abilities. In eight out of 10 studies that conducted robot-mediated interventions related to communication, the intervention improved children's and youth's expression behavior and syntax expression, in particular it contributed to an increase in average length of story, and also promoted the acquisition of sight words, resulting in an increase in the rate of reading words accurately and a decrease in the rate of not being able to read words within a given period of time. It also improved the vocalization of children and youth with minimal speaking, increased communication using AAC and other various communication functions, and increased the number of sentences used.

Next, most of the studies conducted robot-mediated intervention and confirmed the effectiveness of utilizing robot on enhancing social abilities of children and youth with disabilities. First, after participating in the robot-mediated intervention, children and youth's social interactions - such as imitation, eye contact, turn-taking performance, participation, selection, and so on - and initiating and responding behaviors (joint attention) increased significantly. The same was true for the use of various play methods and symbolic play-related behaviors. Furthermore, in a study that examined the effects of robot-mediated intervention by comparing the outcomes between robot-mediated intervention and human-led intervention, children's joint attention and adaptive behavior significantly increased under the robot-mediated intervention condition compared to human-led intervention. Accordingly, it appeared that the robot-mediated intervention was effective for children's social abilities, such as showing very high satisfaction in the interaction with robots (Kostrubiec et al., 2020; Pop et al., 2013).

However, some studies reported that there were no intervention effects found on children's and youth's cooperative behavior, eye contact, symbolic play-related behavior, and joint attention skills when working with their siblings without disabilities (Huskens et al., 2015; 
So et al., 2019; Yun et al., 2015; Zheng et al., 2020). In some other studies, it was confirmed that robot-mediated intervention showed lower effects, when compared with the effects of using non-robot media, such as humans or computers. Also, some researchers reported that they did not see any significant effect of robot-mediated intervention by confirming that there was little difference in the outcomes of the conditions for the dependent variables (Jeong, 2015; Kwon \& Kim, 2013).

\section{DISCUSSION}

In this section, we will discuss the implications of these results for future robotic research.

First, it was found that robot-mediated intervention for children and youth with disabilities was most applied to elementary school students in terms of age and to children and youth with ASD in terms of disability types. Only one among 32 studies was conducted on secondary students with disabilities. Since intervention using robots is still in its infancy

It is considered more appropriate for elementary school students who can cover simpler content than secondary students because. However, the fact that $81.3 \%$ of the analyzed studies were conducted on children and youth with ASD seems to be the result of the research trends that continued to some extent as the previous research using robots for the intervention in children and youth with disabilities was also centered on children and youth with ASD (Diehl, Schmitt, Villano, \& Crowell, 2012). Furthermore, considering the characteristics of ASD, which hinder social interactions, including eye contact with others, the fact that robot-mediated intervention is more advantageous for ASD than for any other disability appears to have contributed to this research trend. However, considering that technology, including robots, has recently been used in interventions among all age groups, it is desirable that the intervention using robots is extended to children and youth of various ages and types of disabilities (Chelvam, Zamin, \& SylviaSteele, 2014; Katz, 2015).

Second, the educational settings and controlled laboratory environments were the most frequent research settings where robot was used for interventions. It is highly desirable that robot-mediated interventions were conducted in real-world educational settings. The fact that more than a third of the selected studies conducted the interventions in controlled settings raises concern. This is not only because the laboratory is more advantageous in creating space and building facilities necessary to control and manipulate robots compared to the actual training sites but also because the laboratory is relatively easy to safely store robots and auxiliary equipment that are expensive and require careful storage. However, considering that robots are already widely used in various daily activities (e.g., robot cleaners) or human services (e.g., robot nurses), more efforts are needed to utilize it in natural environments. In order to take advantage of modern technology, including robots, in the adult lives that children and youth with disabilities will find themselves in after high school, robotic intervention programs should be devised in a natural environment, not just in a defined way for a limited time.

Third, studies that conducted robot-mediated intervention used various research methods, but the most frequently used design was a single-subject design. There were only six group comparison studies, and among them, five used a randomized controlled trial. This is because a considerable number of analyzed studies have conducted interventions in a one-on-one form with a small number of robots because it required considerable cost and manpower to produce several robots at once and apply them to a large number of children and youth. Considering that robot-mediated intervention in the special education field has not yet accumulated enough evidence to become an evidence-based practice, this trend of research design is understandable. Four out of 32 studies used qualitative research methods, mainly to observe children's and youth's reactions to robots. Although the number of studies is not extensive, it is considered encouraging to attempt to examine the effects of robot-mediated interventions in a qualitative manner, rather than relying solely on quantitative measurements. Children's and youth's reactions to the existence of robots themselves and their responses to robot-mediated interventions require an in depth qualitative consideration, and it is necessary to study how to improve the social validity of robot-mediated interventions by qualitatively exploring the perceptions of children and youth, teachers, and parents about robots used in educational practices through interviews or participatory observations.

Fourth, most of the robots used for the intervention were humanoid robots, and the representative areas were joint attention and social interaction skills. In addition, 
robots led the intervention in about half of the analyzed studies, and in the other half, robots assisted the teacher. Joint attention and social interaction skills are representative difficulties of children and youth with ASD, and the most frequent interventions aimed at these areas are likely linked to the fact that children and youth with ASD were the largest number of participants in the analyzed studies. Based on the literature gathered so far, it is difficult to assess whether leading or assisting interventions prove to be more effective and efficient. Future research will need to consider how to distribute roles between robots and teachers to maximize the educational effect.

The limitations of the study are as follows: firstly, it was difficult to control the quality level of the studies because they were chosen based on the selection criteria of research that conducted interventions using robots for children and youth with disabilities. Some of the selected studies did not provide specific details, requiring analysis as it contained limited information. If robots are more actively used in the education and intervention of children and youth with disabilities in the future and more research is conducted, it is necessary to select studies based on a certain level of qualitative indicators (e.g., Gersten \& Edyburn, 2007) and conduct a literature analysis. Secondly, this study did not elaborate on the technical aspects of robots because the purpose of this study was to examine the use of robots in educational settings. Robots do not think, judge, and intervene autonomously like humans but, rather, have a built-in system and intervene through external control, which includes a considerable amount of robotic engineering procedures. Although this study has not conducted such an engineering analysis, it is necessary to analyze the engineering aspects of robots used for intervention for children and youth with disabilities through transdisciplinary research with robots and artificial intelligence experts in the future.

Despite the above mentioned limitations, the present study is meaningful since the author selected studies that used robots to improve communication and social abilities of children and youth with disabilities over the last two decades to examine the effects of robots in the interventions described. Additionally, it provided a general overview to understand the trends of the interventions. Furthermore, this study examined in detail the types of robots used for interventions and their roles. It is no longer new or unfamiliar to actively utilize artificial intelligence-based technologies, including robots, for intervention and education of children and youth with disabilities. Now, our mission is to maximize the access and efficiency of technology so that it can have a direct effect on the motivation, learning, communication, and social abilities of children and youth with disabilities. To this end, transdisciplinary research that encompasses special education, artificial intelligence, and robotics, needs to be conducted, and financial aid should be provided to enable the introduction of these advanced engineering technologies to special education setting.

\section{ACKNOWLEDGEMENT}

None.

DISCLOSURE STATEMENT

No potential conflict of interest was reported by the authors.

\section{FUNDING:}

This work was supported

by the Technology Innovation Program

(20003762, Development of a screening

and training robot system

with 95 percent behavioral recognition

based on $\mathrm{HRI}$ for children

with developmental disorder)

funded by the Ministry of Trade,

Industry \& Energy (MOTIE, Korea). 


\begin{tabular}{|c|c|c|c|c|c|c|c|c|c|c|c|}
\hline 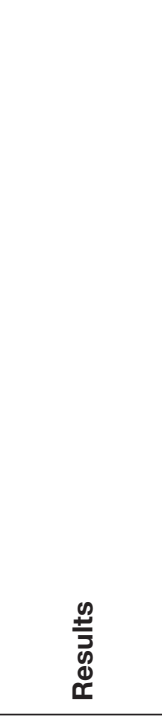 & 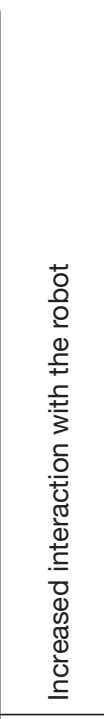 & 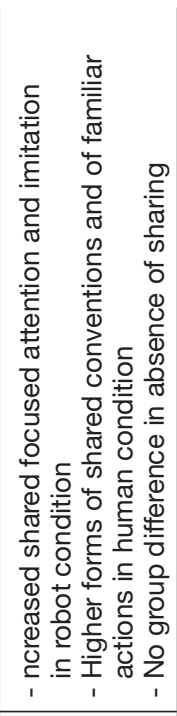 & 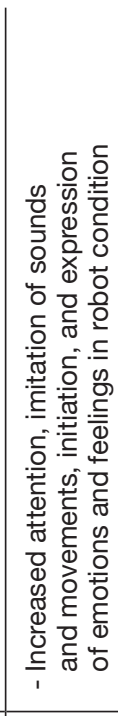 & 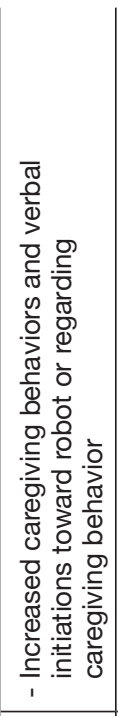 & 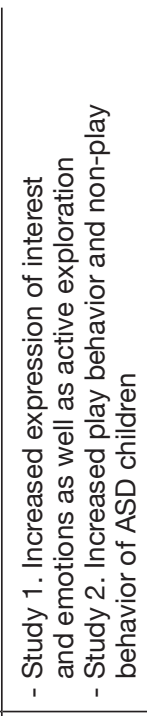 & 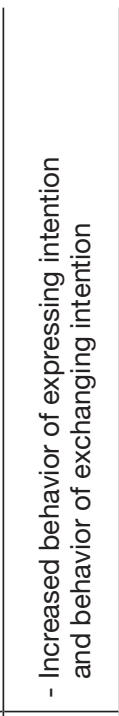 & 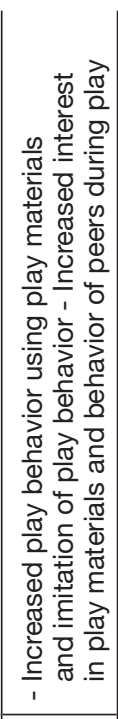 & 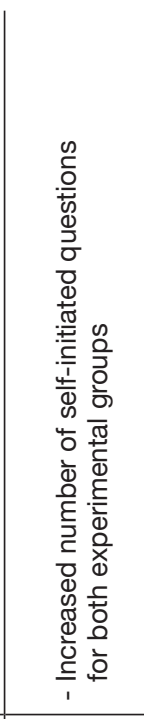 & 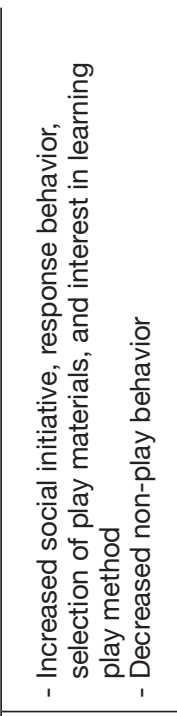 & 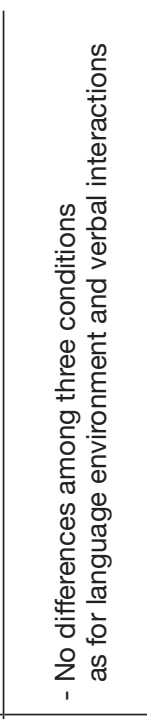 & 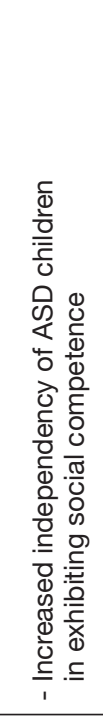 \\
\hline 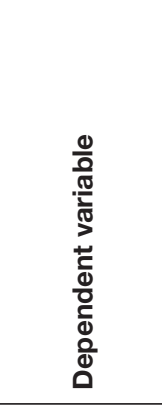 & 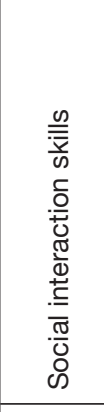 & 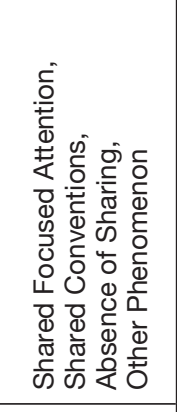 & 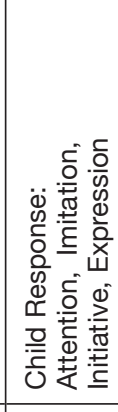 & 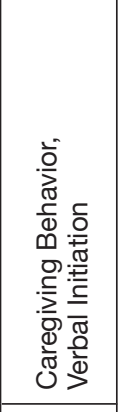 & 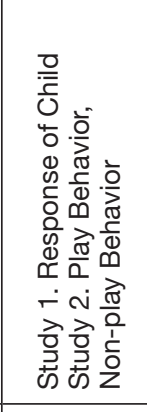 & 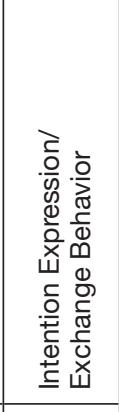 & 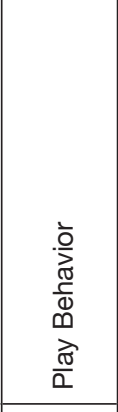 & 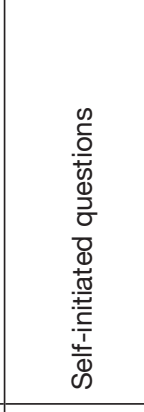 & 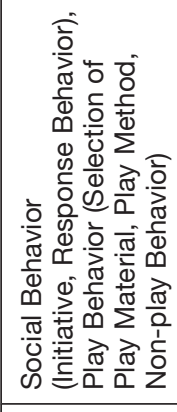 & 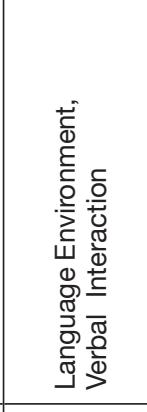 & $\begin{array}{l}0 \\
\infty \\
\check{0} \\
0 \\
00 \\
0 \\
\simeq \\
\frac{\pi}{0} \\
\frac{\sigma}{0} \\
\infty\end{array}$ \\
\hline 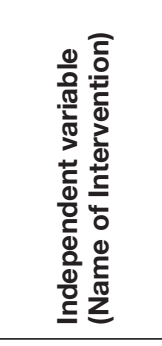 & 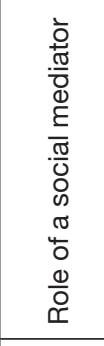 & 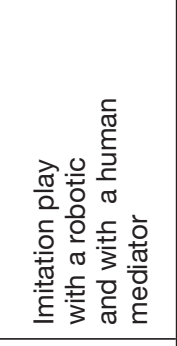 & 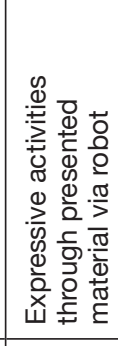 & 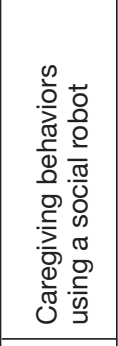 & 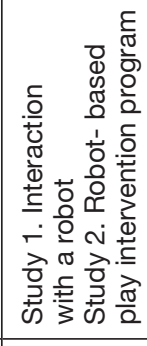 & 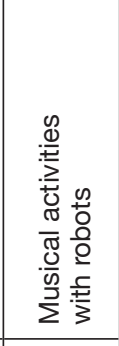 & 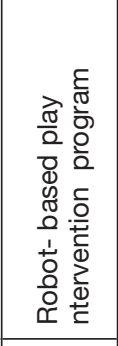 & 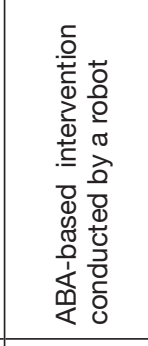 & 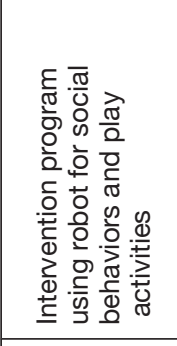 & 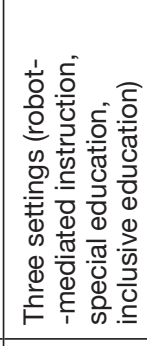 & 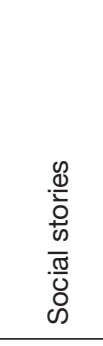 \\
\hline 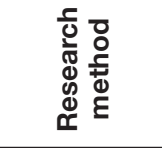 & $z \frac{\widehat{\Phi}}{\frac{0}{D}}$ & $z \frac{\widehat{d}}{\frac{0}{0}}$ & $\vec{\sigma}$ & 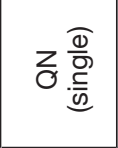 & 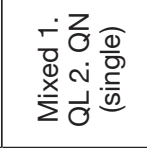 & ठ & $\vec{\sigma}$ & $z \frac{\widehat{\frac{\omega}{D}}}{\frac{. \bar{\omega}}{\omega}}$ & 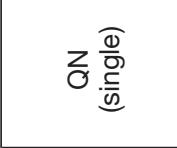 & 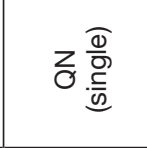 & zo \\
\hline 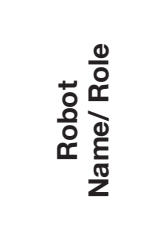 & 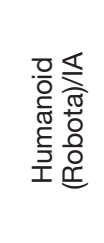 & 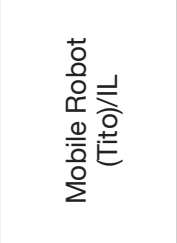 & 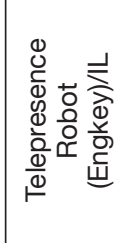 & 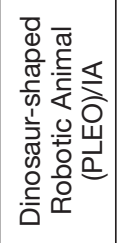 & 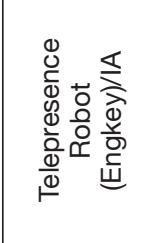 & 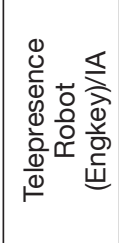 & 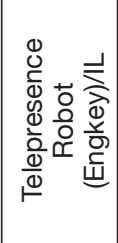 & 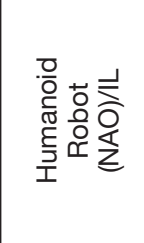 & 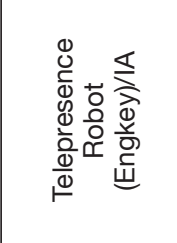 & 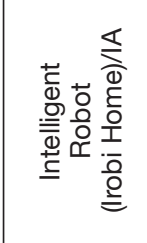 & 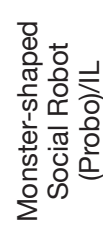 \\
\hline 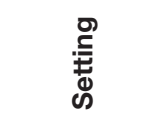 & 只 & $\vdash$ & 邑 & $\vdash$ & 邑 & 㞻 & 미 & $\vdash$ & $\Sigma$ & 只 & 冓 \\
\hline 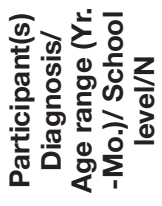 & 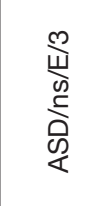 & 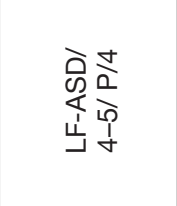 & 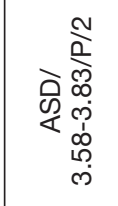 & 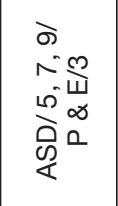 & $\begin{array}{l}\grave{b} \\
\frac{1}{d} m \\
\frac{0}{\alpha}\end{array}$ & 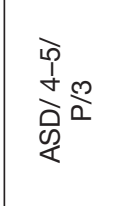 & $\begin{array}{l}\grave{p} \\
m \\
\frac{m}{a}\end{array}$ & 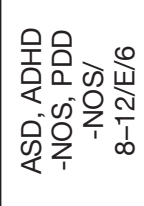 & $\begin{array}{l}\grave{\phi} \\
\dot{+} \\
\dot{0}\end{array}$ & 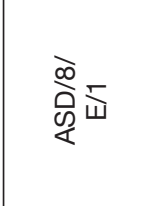 & 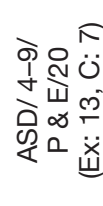 \\
\hline 竞焉 & 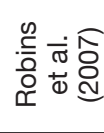 & 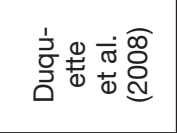 & 로웜 & c气 & ఖ్ల్ & ® & 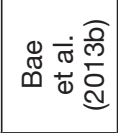 & 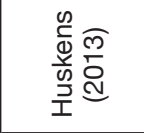 & 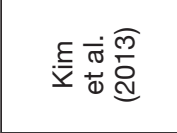 & 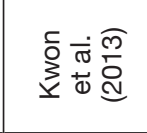 & 융웜 \\
\hline$\stackrel{\circ}{z}$ & - & $\sim$ & m & $\checkmark$ & مـ & 0 & ^ & $\infty$ & $\sigma$ & 음 & \\
\hline
\end{tabular}




\begin{tabular}{|c|c|c|c|c|c|c|c|c|c|c|}
\hline 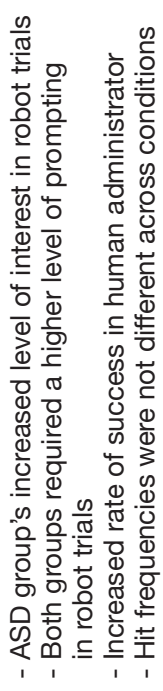 & 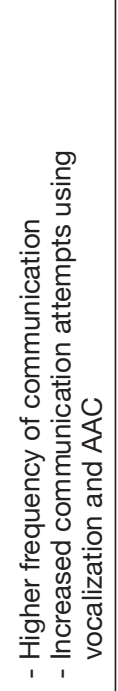 & 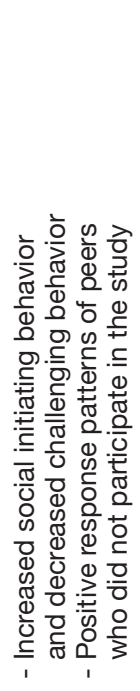 & 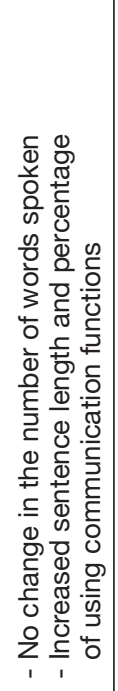 & 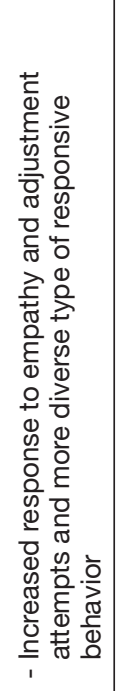 & 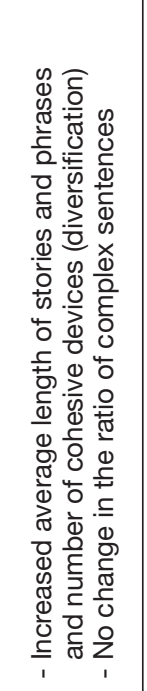 & 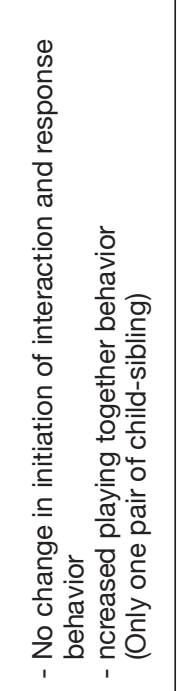 & 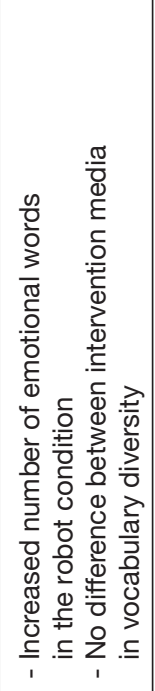 & 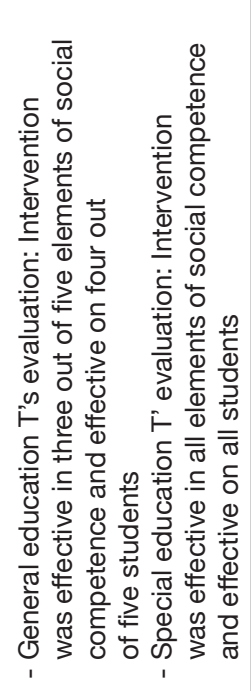 & 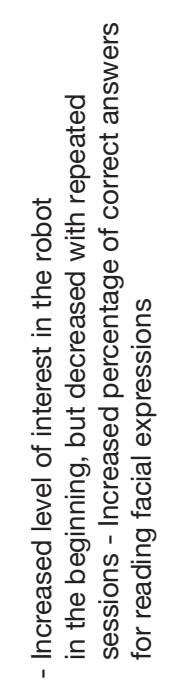 & 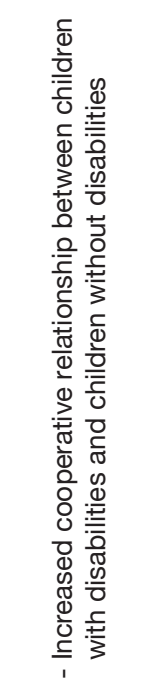 \\
\hline 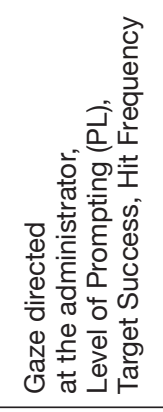 & 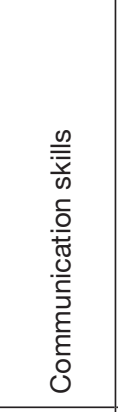 & 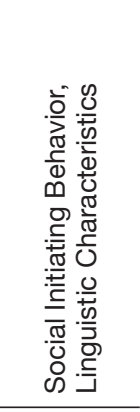 & 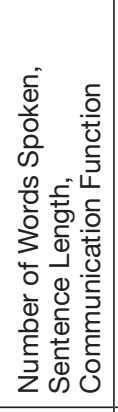 & 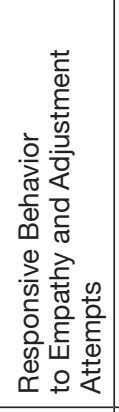 & 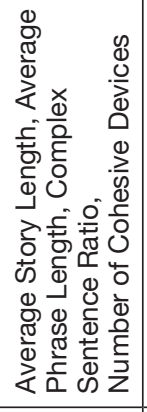 & 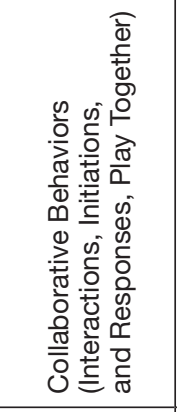 & 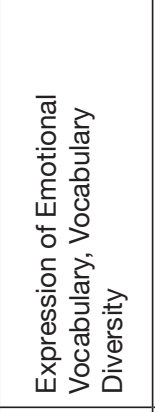 & 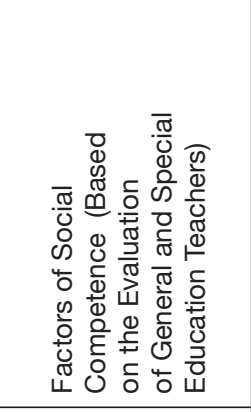 & 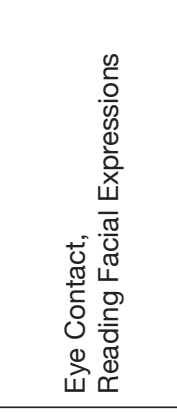 & 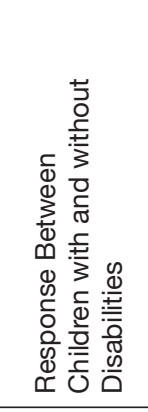 \\
\hline 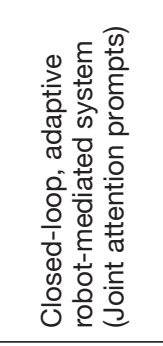 & 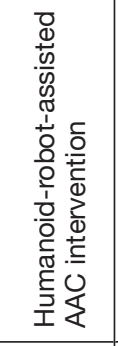 & 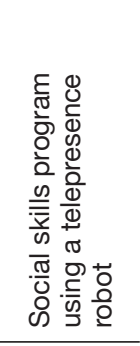 & 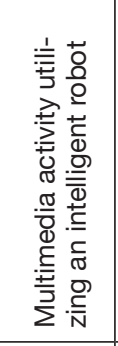 & 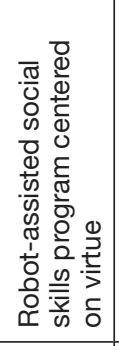 & 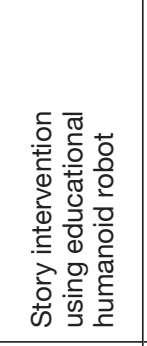 & 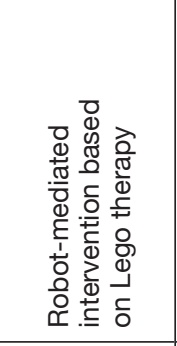 & 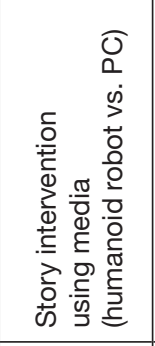 & 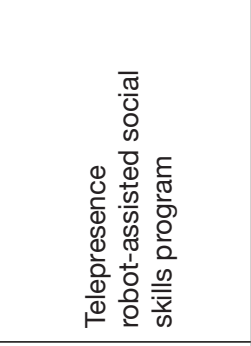 & 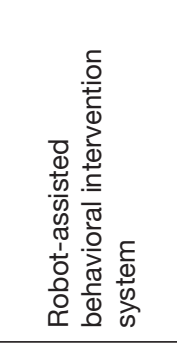 & 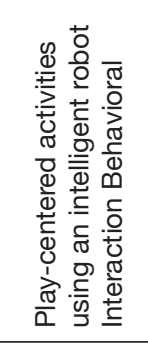 \\
\hline zo & $z \stackrel{\frac{\widehat{\omega}}{0}}{\frac{.}{\omega}}$ & 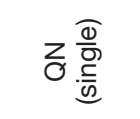 & $z_{0} \frac{\widehat{\widehat{\omega}}}{\underline{\underline{\omega}}}$ & 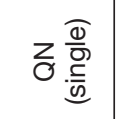 & $z_{0} \frac{\widehat{\Phi}}{\underline{\underline{\omega}}}$ & zo & zo 产 & zo & 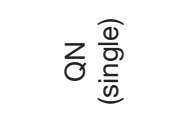 & $\vec{\sigma}$ \\
\hline 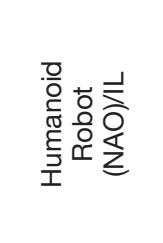 & 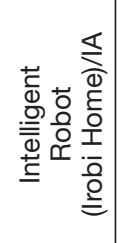 & 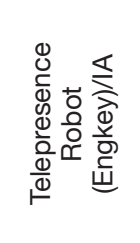 & 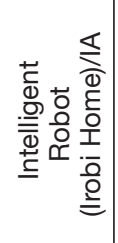 & 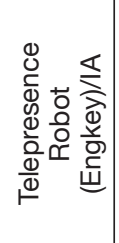 & 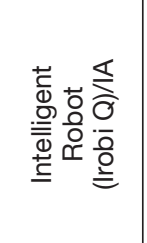 & 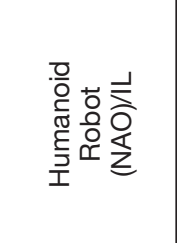 & 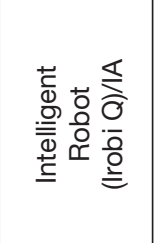 & 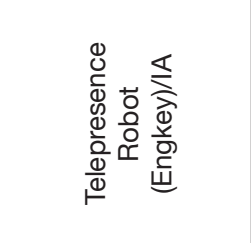 & 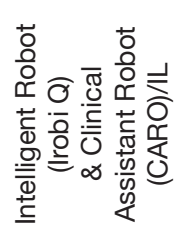 & 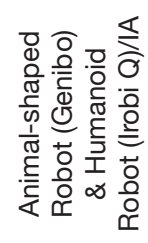 \\
\hline$\vdash$ & $\vdash$ & 邑 & 이 & 요 & $I$ & $\vdash$ & $\Sigma$ & 미 & $\stackrel{N}{Z}$ & 미 \\
\hline 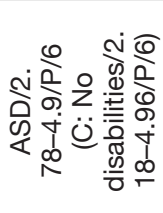 & 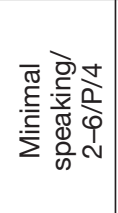 & 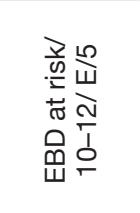 & 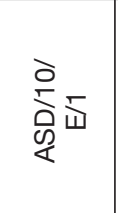 & 욤ํำ & 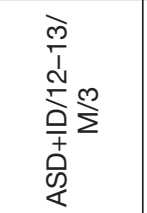 & 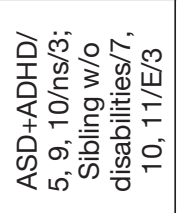 & 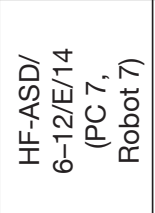 & 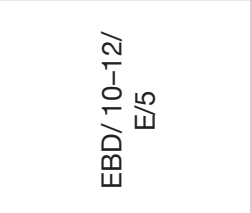 & 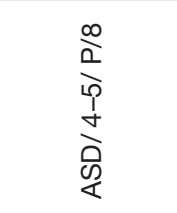 & 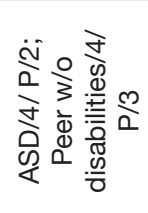 \\
\hline 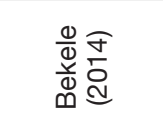 & 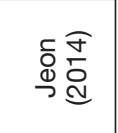 & 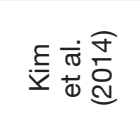 & $\stackrel{\Phi}{\Phi} \stackrel{\sigma}{\stackrel{\sigma}{g}}$ & 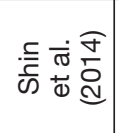 & 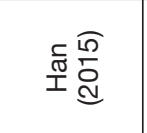 & 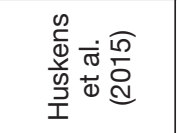 & 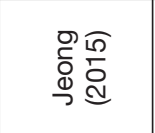 & 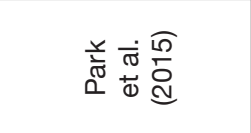 & 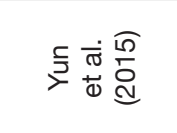 & 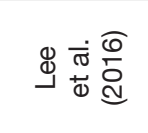 \\
\hline$\stackrel{\simeq}{\simeq}$ & $\stackrel{m}{\longrightarrow}$ & $\stackrel{\nabla}{\sim}$ & $\stackrel{\circ}{r}$ & 6 & 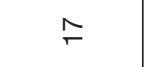 & $\stackrel{\infty}{\sim}$ & $\stackrel{ }{\square}$ & ㄱ & $\bar{N}$ & $\approx$ \\
\hline
\end{tabular}




\begin{tabular}{|c|c|c|c|c|c|c|c|c|c|c|c|}
\hline 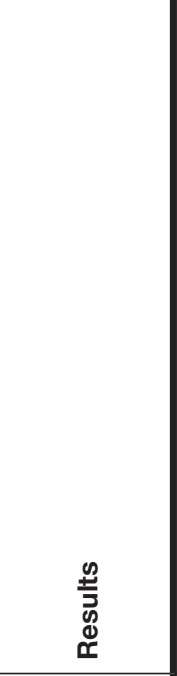 & 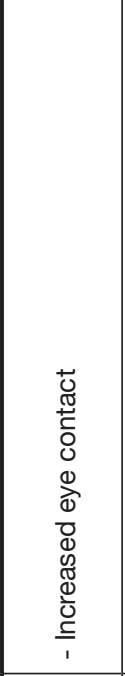 & 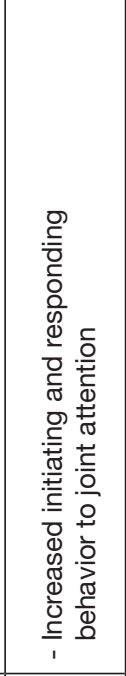 & 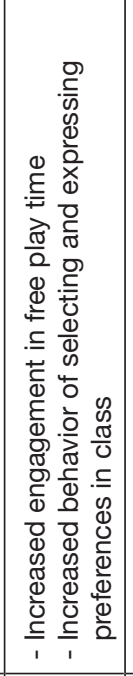 & 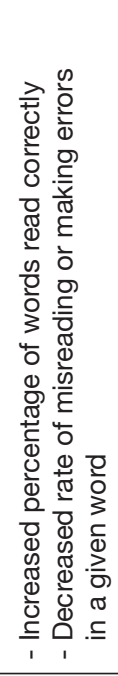 & 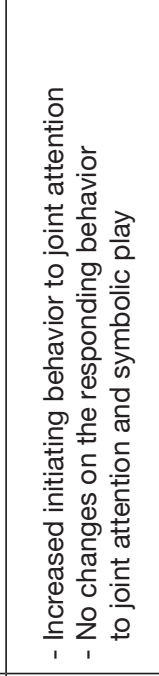 & 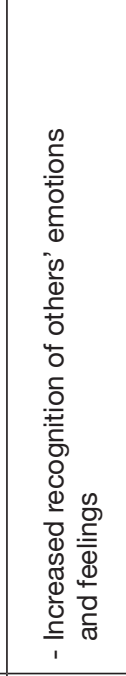 & 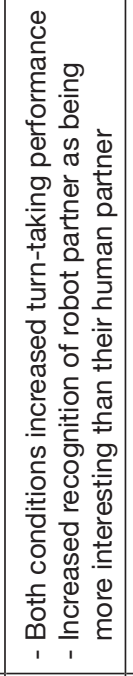 & 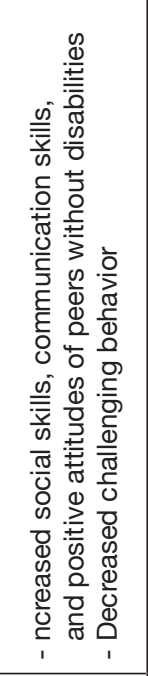 & 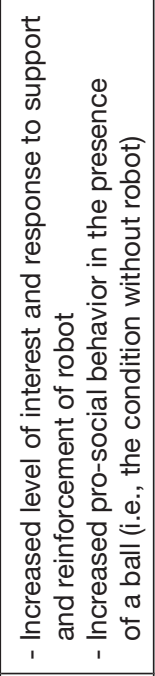 & 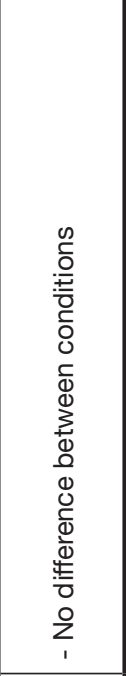 & \\
\hline 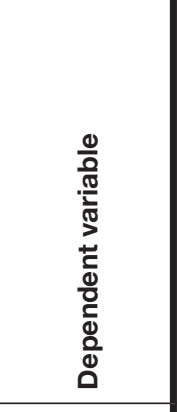 & 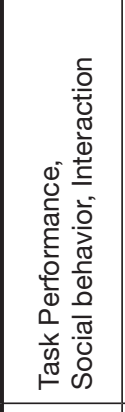 & 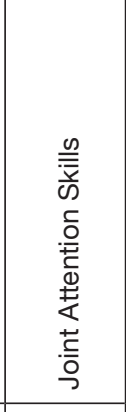 & 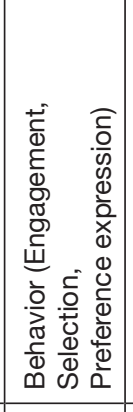 & 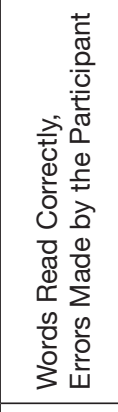 & 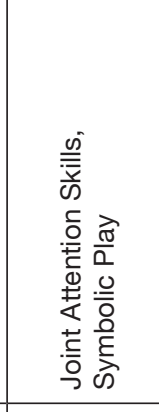 & 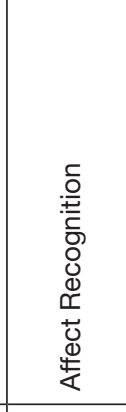 & 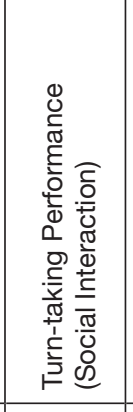 & 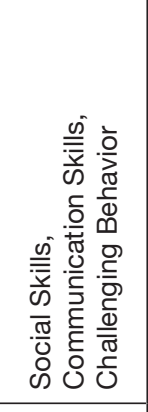 & 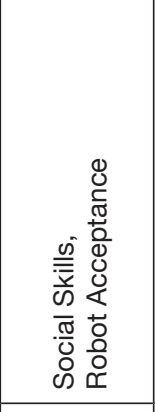 & 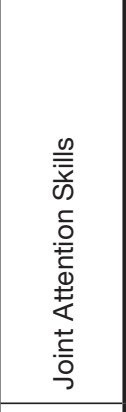 & \\
\hline 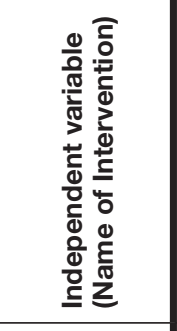 & 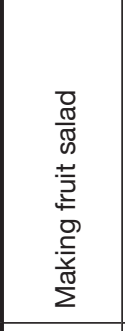 & 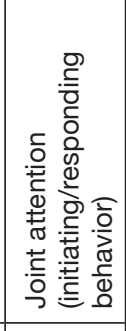 & 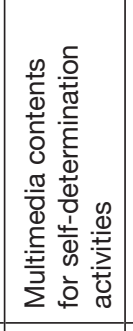 & 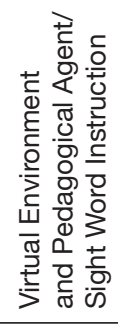 & 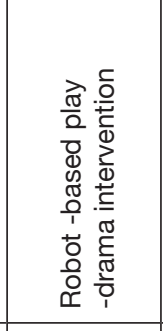 & 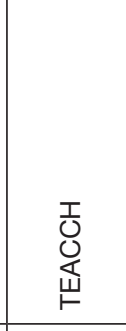 & 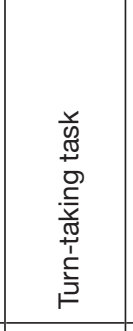 & 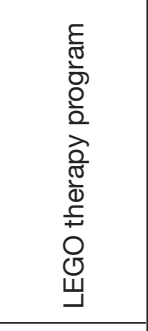 & 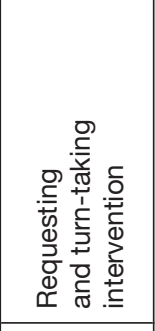 & 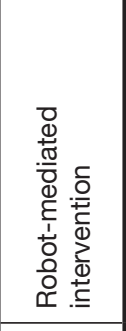 & 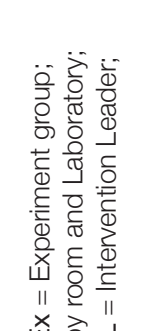 \\
\hline 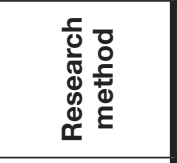 & zo & 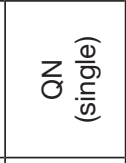 & $z \frac{\widehat{\frac{\omega}{0}}}{\frac{. c}{\omega n}}$ & 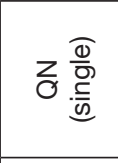 & 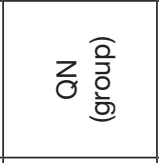 & 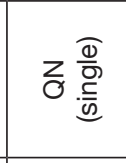 & 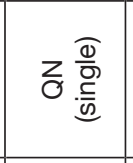 & $z \frac{\widehat{d}}{\frac{0}{0}}$ & z & z & 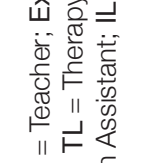 \\
\hline 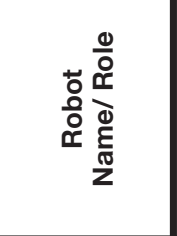 & 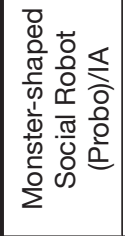 & 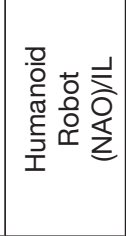 & 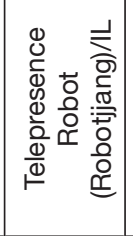 & 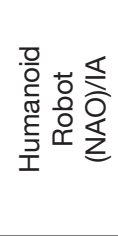 & 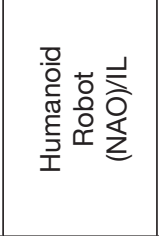 & 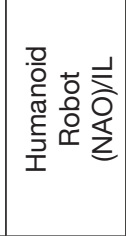 & 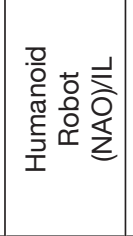 & 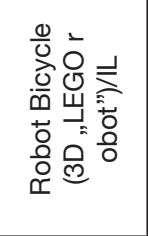 & 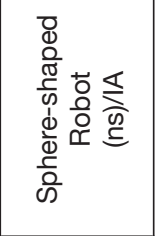 & 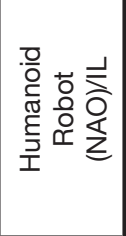 & 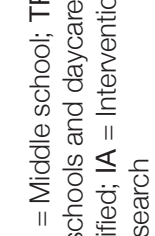 \\
\hline 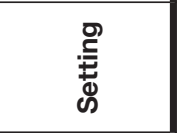 & 只 & 오 & 只 & $\vdash$ & $\vdash$ & $\vdash$ & $\vdash$ & 邑 & $\stackrel{\infty}{2}$ & $\vdash$ & 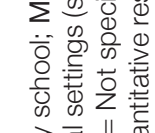 \\
\hline 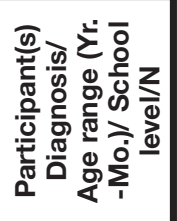 & 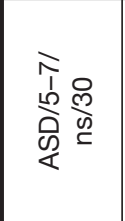 & $\stackrel{\infty}{\text { के }}$ & 突变 & 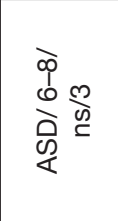 & 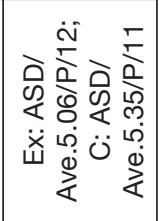 & 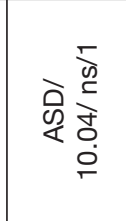 & 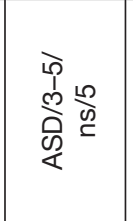 & 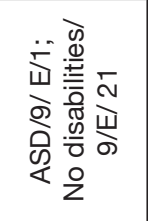 & 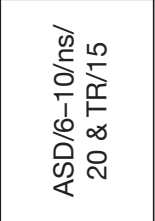 & 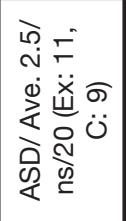 & 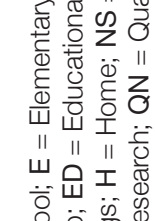 \\
\hline 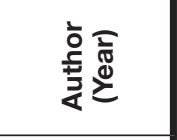 & 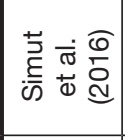 & 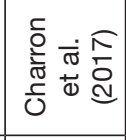 & 立 $\frac{\alpha}{d}$ & 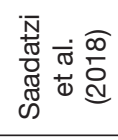 & 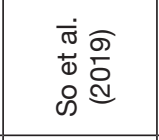 & 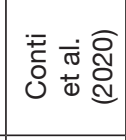 & 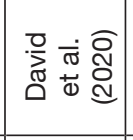 & 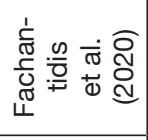 & 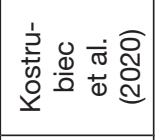 & 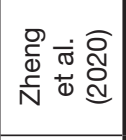 & \\
\hline 은 & $\stackrel{\varpi}{\sim}$ & $\stackrel{\text { N }}{ }$ & $\stackrel{\sim}{\sim}$ & $\stackrel{\circ}{\sim}$ & $\hat{N}$ & $\stackrel{\infty}{\sim}$ & $\stackrel{2}{N}$ & ి్ల & " & ల్ల & \\
\hline
\end{tabular}




\section{REFERENCES}

Bae, M. J. (2013). A study on the effects of a robot-based play intervention program on the play behaviors of young children with autism spectrum disorder (Doctoral dissertation). Daegu University, Daegu, Korea.

Bae, M. J., \& Lee, H. S. (2013). An investigation into the intention expression behavior of young children with the autism spectrum disorder - The qualitative analysis of musical activities with robots - Journal of Special Education \& Rehabilitation Science, 52(2), 143-166.

Bae, M. J., Lee, H. S., Park, C. J., \& Kim, J. H. (2013). A study on the play behavior of young children with developmental delays in inclusive free play - With a focus on small group free play after the implementation of a robot-based play intervention program -. Journal of Special Education \& Rehabilitation Science, 52(1), 355-384.

Bekele, E., Crittendon, J. A., Swanson, A., Sarkar, N., \& Warren, Z. E. (2014). Pilot clinical application of an adaptive robotic system for young children with autism. Autism, 18(5), 598-608.

Charron, N., Lewis, L., \& Craig, M. (2017). A robotic therapy case study: Developing joint attention skills with a student on the autism spectrum. Journal of Educational Technology Systems, 46(1), 137-148.

Chelvam, Y. K., Zamin, N., \& SylviaSteele, G. S. (2014). A preliminary investigation of M3DITRACK3R: A medicine dispensing mobile robot for senior citizens. Procedia Computer Science, 42, 240-246.

Choi, E. Y. (2015). Literature review of robots used for the rehabilitation of children with autistic spectrum disorder. Journal of rehabilitation welfare engineering \& assistive technology, 9(4), 265-273.

Conti, D., Trubia, G., Buono, S., Di Nuovo, S., \& Di Nuovo, A. (2020). Affect recognition in autism: a single case study on integrating a humanoid robot in a standard therapy. Qwerty-Open and Interdisciplinary Journal of Technology, Culture, and Education, 14(2), 66-87.

Dautenhahn, K., \& Billard, A. (2002). Games children with autism can play with Robota, a humanoid robotic doll. In S. Keates, PJ. Clarkson, PM. Langdon, P. Robinson (Eds.), Universal access and assistive technology. (pp. 179-190). London, United Kingdom: Springer-Verlag.

David, D. O., Costescu, C. A., Matu, S., Szentagotai, A., \& Dobrean, A. (2020). Effects of a robot-enhanced intervention for children with ASD on teaching turn-taking skills. Journal of Educational Computing Research, 58(1), 29-62.

Diehl, J. J., Schmitt, L. M., Villano, M., \& Crowell, C. R. (2012). The clinical use of robots for individuals with autism spectrum disorders: A critical review. Research in Autism Spectrum Disorders, 6(1), 249-262.

Duquette, A., Michaud, F., \& Mercier, H. (2008). Exploring the use of a mobile robot as an imitation agent with children with low-functioning autism. Autonomous Robots, 24(2), 147-157.

Fachantidis, N., Syriopoulou-Delli, C. K., Vezyrtzis, I., \& Zygopoulou, M. (2020). Beneficial effects of robot-mediated class activities on a child with ASD and his typical classmates. International Journal of Developmental Disabilities, 66(3), 245-253.

Fettig, A., \& Barton, E. E. (2014). Parent implementation of function-based intervention to reduce children's challenging behavior: A literature review. Topics in Early Childhood Special Education, 34(1), 49-61.

Gersten, R., \& Edyburn, D. (2007). Defining quality indicator for special education technology research. Journal of Special Education Technology, 22(3), 3-18.

Han, B. Y. (2015). The effect of a story intervention using educational humanoid robot on syntactic skills of children with autism spectrum disorders (Master's dissertation). Ewha Womans University, Seoul, Korea.

Huskens, B., Palmen, A., Van der Werff, M., Lourens, T., \& Barakova, E. (2015). Improving collaborative play between children with autism spectrum disorders and their siblings: The effectiveness of a robot-mediated intervention based on Lego@ therapy. Journal of autism and developmental disorders, 45(11), 3746-3755.

Huskens, B., Verschuur, R., Gillesen, J., Didden, R., \& Barakova, E. (2013). Promoting question-asking in school-aged children with autism spectrum disorders: Effectiveness of a robot intervention compared to a human-trainer intervention. Developmental neurorehabilitation, 16(5), 345-356.

Jeon, K. H. (2014). The effect of AAC intervention using humanoid robot on ability of communicative expression of pre-schooler children with minimally verbal (Master's dissertation). Ewha Womans University, Seoul, Korea.

Jeong, M. K. (2015). Lexical representation of emotions for high function autism via story program intervention using smart media (humanoid robot vs. PC) (Master's dissertation). Ewha Womans University, Seoul, Korea.

Kang, J. H., Kim, C. G., Lee, S. H., \& Song, B. S. (2007). Development of walking assistance robot for the blind. Journal of the Korean Sensors Society, 16(4), 286-293.

Katz, R. (2015). Tele-care robot for assisting independent senior citizens who live at home. Studies in Health Technology \& Informatics, 217, 288-294.

Kim, S. J. (2018). The effects of an increase in self-determination experience on the behavior of young children with autism spectrum disorder by telepresence robot. Journal of Rehabilitation Welfare Engineering \& Assistive Technology, 12(1), 38-45.

Kim, B. J., \& Han, J. H. (2005). Analysis on psychological and educational effects in children and home robot interaction. Journal of the Korean Association of Information Education, 9(3), 501-510.

Kim, J. H., Kim, S. J., Lee, H. S., Shin, Y. H., Park, C. J., Kang, J. B., \& Kim, C. G. (2014). Using a peer robot to improve the social skills of children at risk for emotional behavioral disorders. Journal of Emotional \& Behavioral Disorders, 30(2), 58-90.

Kim, K. H., Lee, H. S., Chang, S. J., \& Bae, M. J. (2011). Teachers' perspectives on the use of a robot for educational purpose for children labeled with autism. Journal of Emotional \& Behavioral Disorders, 27(2), 159-178.

Kim, K. H., Lee, H. S., Kim, J. H., Cho, J. M., \& Kim, S. H. (2012). Learning expressive activities to children with autism through material presented via robot. Journal of Emotional \& Behavioral Disorders, 28(2), 325-347. 
Kim, J. H., Lee, H. S., Park, C. J., Bae, M. J., \& Kang, J. B. (2013). Effects of intervention program using on social behavior and play activities for young children with developmental delay. The Journal of Special Children Education, 15(1), 1-28.

Kim, C. G., Lee, H. S., Shin, Y. H., Kang, J. B., Kim M. S., Choi, M. T., \& Song, B. S. (2012). Establishment of remote support system for children with disabilities through the use of robots. Journal of Special Education \& Rehabilitation Science, 51(1), 327-347.

Kim, S. B., \& Shin, Y. H. (2014). A review of studies on the application of robots for improvement of social skills for children with autistic spectrum disorder and emotional and behavioral disorder. Journal of Special Education and \& Rehabilitation Science, 53(4), 21-52.

Kim, C. G., \& Song, B. S. (2012). Studies on application of robot remote support system: Focused on special education. Journal of Special Education \& Rehabilitation Science, 51(4), 95-110.

Kostrubiec, V., \& Kruck, J. (2020). Collaborative research project: developing and testing a robot-assisted intervention for children with autism. Frontiers in Robotics and Al, 7(37), 1-16.

Kwon, J. M., \& Kim, Y. T. (2013). Language environment and interaction of a child with moderate autism: Comparison of robot-mediated instruction, special education, and inclusive education settings. Journal of the Korean Association for Persons with Autism, 13(3), 19-38.

*Lee, Y. L. (2014). The effects of an activity using an intelligent robot on the communication of child with autism (Master's dissertation). Seoul National University of Education, Seoul, Korea.

Lee, Y. S., \& Cho, G. M. (2016). A study on play-centered activities using an intelligent robot in an inclusive early childhood special education, Journal of Early Childhood Education, 36(3), 491-511.

Lee, S. H., \& Park, E. H. (2011). Teaching exceptional children in inclusive settings: Special education guide for integrated class teachers (3rd edition). Seoul: Hakjisa.

Park, C. J., Shin, Y. H., Lee, H. S., Kim, J. H., Kim, S. J., Kang, J. B., \& Kim, C. G. (2015). The study on effect of intervention for improving social skill using tele-presence robot for children with emotional and behavioral disorder at risk. Journal of Emotional \& Behavioral Disorders, 31(1), 397-415.

Pop, C. A., Simut, R. E., Pintea, S., Saldien, J., Rusu, A. S., Vanderfaeillie, J.,David, D. O., Lefeber, D., \& Vanderborght, B. (2013). Social robots vs. computer display: does the way social stories are delivered make a difference for their effectiveness on ASD children? Journal of Educational Computing Research, 49(3), 381-401.

Robins, B., \& Dautenhahn, K. (2007). Encouraging social interaction skills in children with autism playing with robots: A case study evaluation of triadic interactions involving children with autism, other people (peers and adults) and a robotic toy. Enfance, 59(1), 72-81.

Saadatzi, M. N., Pennington, R. C., Welch, K. C., \& Graham, J. H. (2018). Small-group technology-assisted instruction: virtual teacher and robot peer for individuals with autism spectrum disorder. Journal of autism and developmental disorders, 48(11), 3816-3830.

Shin, Christine. (2012). Caregiving behavior training with an animal robot for children with autism spectrum disorder (Master's dissertation). Sungkyunkwan University, Seoul, Korea.

Shin, Y. H., Park, C. J., Lee, H. S., Kim, J. H., Kim. S. J., Kang, J. B., \& Kim, C. G. (2014). A study on the response of empathic and negotiatory initiations of the children at risk for emotional and behavioral disorders through the telepresence robot assisted intervention. Journal of Emotional \& Behavioral Disorders, 30(3), 123-150.

Silvera-Tawil, D., Bradford, D., \& Roberts-Yates, C. (2018). Talk to me: The role of human-robot interaction in improving verbal communication skills in students with autism or intellectual disability. Proceedings of the 2018 27th IEEE International Symposium on Robot and Human Interactive Communication (RO-MAN), 1-6.

Silvera-Tawil, D., \& Roberts-Yates, C. (2018). Socially-assistive robots to enhance learning for secondary students with intellectual disabilities and autism. Proceedings of the 2018 27th IEEE International Symposium on Robot and Human Interactive Communication (RO-MAN), 838-843.

Simut, R. E., Vanderfaeillie, J., Peca, A., Van de Perre, G., \& Vanderborght, B. (2016). Children with autism spectrum disorders make a fruit salad with probo, the social robot: An interaction study. Journal of autism and developmental disorders, 46(1), 113-126.

So, W. C., Cheng, C. H., Lam, W. Y., Wong, T., Law, W. W., Huang, Y., Ng. K. C., Tung. H. C., \& Wong, W. (2019). Robot-based play-drama intervention may improve the narrative abilities of Chinese-speaking preschoolers with autism spectrum disorder: A pilot study. Journal of Autism and Developmental Disorders, 95,1-15.

Song, S, M., Kim, E. H., \& Kwak, J. R. (2020). Analysis of social robot usage patterns and satisfaction of students with physical disabilities. Korean Journal of Physical, Multiple \& Health Disabilities, 63(3), 167-196.

Yun, S. S., Kim, H. S., Choi, J. S., \& Park, S. K. (2015). A robotic system with behavioral intervention facilitating eye contact and facial emotion recognition of children with autism spectrum disorders. Journal of Korea Robotics Society, 10(2), 61-69.

Zheng, Z., Nie, G., Swanson, A., Weitlauf, A., Warren, Z., \& Sarkar, N. (2020). A randomized controlled trial of an intelligent robotic response to joint attention intervention system. Journal of Autism and Developmental Disorders, 50, 2819-2831. 